\title{
TRANSFORMAÇÃO URBANA: UM ESTUDO DE CASO DO BAIRRO DE CACUPÉ, FLORIANÓPOLIS, SC
}

\author{
URBAN TRANSFORMATION: A CASE STUDY IN CACUPÉ DISTRICT, \\ FLORIANÓPOLIS, SANTA CATARINA, BRAZIL
}

\author{
FILÁRTIGA, Marila \\ Arquiteta e urbanista, mestranda do Programa de Pós-Graduação em Arquitetura e Urbanismo (POSARQ) \\ da Universidade Federal de Santa Catarina. \\ E-mail: marila@gebaraefilartiga.arq.br
}

\section{SANTIAGO, Alina}

Professora doutora do POSARQ/UFSC, Departamento de Arquitetura e Urbanismo, Universidade Federal de Santa Catarina e coordenadora do Grupo de Pesquisa de Informática na Arquitetura - INFOARQ/ UFSC.E-mail: alina@arq.ufsc.br

\section{RESUMO}

As cidades hoje estão em um constante processo de transformação. $\bigcirc$ Brasil vive ainda em sua historia uma urbanização acelerada. Passou, em 50 anos, de uma ocupação rural para urbana. Essa transformação ocorreu basicamente no século XX, influenciada pela revolução industrial. Hoje a população do país é de 169.799 .170 hab., sendo $80 \%$ vivendo em área urbana. (IBGE, Censo Demográfico 2000).

Esse estudo tem como objetivo analisar a transformação urbana no bairro de Cacupé em Florianópolis, SC, identificando as vantagens e desvantagens pela percepção da população nativa.

Palavras-chave: Espaço urbano, transformação urbana, segregação.

\begin{abstract}
The cities are in a contínuos tranformation process. Brazil in especial, still lives its accelereted urbanization history. The century has changed from a rural ocupation to a urban ocupation in 50 years. This tranformation occured basicaly in a XX century, influenced by the Industrial Revolution.

Today the brazilian population is 169.799 .170 hab, $80 \%$ of which living in the urban area (IBGE, Demographic Census 2000).

The study objectives to analise this urbans transformation showing its advantages and disadvantages and how the native population reacts over this new reality. The objective os study is the Cacupe district in the city of Florianopolis, SC, Brazil.
\end{abstract}

Key words: Urban space, urban transformation, segregation.

\section{Introdução}

Hoje é fácil observar problemas típicos nas cidades, por um lado: "periferias longínquas e desprovidas de serviços e equipamentos urbanos essenciais; favelas, invasões, vilas e alagados nascem e se expandem; a retenção especulativa de terrenos...; o adensamento e a verticalização sem precedentes,..."(OLIVEIRA, 2001). E por outro lado, lugares providos de infra-estrutura, cercado de conforto e segurança. Essa desigualdade decorrente do processo de urbanização é injusta e fruto do descaso e da atenção voltada apenas para o setor de maior poder aquisitivo 34 da população.

Existe uma confluência de interesses privados que desejam manter a cidade como uma máquina de crescimento. Esses interesses historicamente se constituíram em um poderoso mecanismo de especulação que concentra riqueza e poder, e nesse mecanismo prevalecem os interesses 
privados sobre os interesses da sociedade como um todo. É baseado no conceito de máquinade-crescimento-urbano que o incorporador atua, um agente com expectativas de apostar em ganhos e um dos responsáveis pelas transformações na cidade porque cria novos lugares para morar.

O último levantamento realizado pela Prefeitura de Florianópolis, entre 2002 e 2003, mostrou que a área total construída na llha aumentou em $28 \%$. O dado é um reflexo da venda de imóveis de alto padrão que dobrou em relação aos dois últimos anos e representou $27 \%$ das transações do segmento no Brasil, entre janeiro e outubro de 2003. Um desses investidores, responsável por dois novos empreendimentos no bairro de Cacupé, fechou o balanço anual de 2003 com saldo positivo de retorno em investimentos e muitas projeções para alavancar a venda de imóveis de alto padrão. Entre seus empreendimentos, quatro deles estão sendo construídos em pontos de moradia considerados nobres para a cidade: Cacupé, Canajurê e Centro, e pretendem movimentar R\$51 milhões.

Esse estudo busca analisar esses novos lugares para morar que surgem com a acelerada transformação da cidade.

\section{Espaço urbano}

A apreensão de espaço urbano é necessária para posterior analise das transformações que estão ocorrendo nesse espaço.

Entender o espaço urbano como uma área delimitada pertencente à cidade, formado por equipamentos ou objetos que constituem essa área, é um pensamento limitado. Cidade é mais do que um aglomerado urbano, é o centro de vida social e política, é um sistema aberto, onde ordem e desordem convivem juntas. Portanto pensar de algo estático, fixo, formado por objetos não corresponde a uma ampla compreensão de espaço urbano. Espaço não é apenas uma área delimitada por objetos, são também, os elementos que estão presentes nele.

Conforme Linch (1997), o espaço urbano, a cidade, não é formada apenas pelos equipamentos e pela paisagem natural é também formada pelas pessoas que vivem nesse espaço.

"Os elementos moveis de uma cidade e, em especial, as pessoas e suas atividades, são tão importantes quanto às partes físicas estacionárias. Não somos meros observadores desse espetáculo, mas parte dele; compartilhamos o mesmo palco com os outros participantes." (LINCH, 1997, p. 2)

Nesse sentido, se a sociedade participa da cidade, suas particularidades irão também interferir nesse espaço. Os estudos do espaço urbano não podem excluir a cultura contida nos elementos que o compõe e nem simplificá-lo a conceitos geográficos.

A paisagem urbana esta ligada tanto às intervenções do homem, através da cultura, quanto aos seus aspectos naturais. Essas intervenções não são estáticas, modificam-se a cada instante e são percebidas de modos diferentes por cada individuo. "A paisagem não é estática, pois todos os seus elementos constituintes são passíveis de transformações próprias, como também se alteram mutuamente" (BURLE MARX, 1987, p. 55). Essa transformação se refere tanto em seus aspectos físicos, a natureza não é estática, quanto humanos, cada individuo estabelece uma cidade de acordo com suas experiências individuais. Um mesmo espaço urbano pode ter significados diversos para cada individuo.

Sendo assim, espaço urbano é tanto a forma geográfica de uma paisagem quanto os elementos que estão contidos nela. Esses elementos são físicos naturais, como as árvores, os morros, os pássaros; são físicos, como as calçadas, as ruas, o poste, o orelhão, a lixeira e são subjetivos, como a experiência individual dos que estão contidos no espaço. A paisagem cultural é modelada a partir de uma paisagem natural por um grupo cultural. Com a introdução de uma cultura 
diferente, estabelece-se um rejuvenescimento da paisagem cultural ou uma nova paisagem se sobrepõe sobre o que sobrou da antiga.

Para Côrrea (1993), espaço urbano é um conjunto de usos da terra organizados. Esses usos que definem as áreas dentro da cidade tornando em um espaço fragmentado. Mas para ele o espaço é também articulado porque envolve a sociedade nas decisões. Sendo fragmentado e articulado simultaneamente, pois as decisões das divisões têm a participação da sociedade, então o espaço urbano é também um reflexo da sociedade.

Nesse sentido, a transformação do espaço urbano é reflexo da sociedade, e portanto caracteriza-se também por desigualdades e segregação, refletindo a realidade do país hoje.

\section{O estudo de caso - Cacupé, Florianópolis-SC}

Florianopolis é capital do estado de Santa Catarina, Brasil. Hoje, a área do município, compreendendo a parte continental e a ilha, tem $436,5 \mathrm{~km}^{2}$, com uma população de 396.778 habitantes em 2005, segundo estimativa do IBGE.

Uma cidade com o setor turístico bastante importante para a economia e um dos fatores de interferem no seu desenvolvimento.

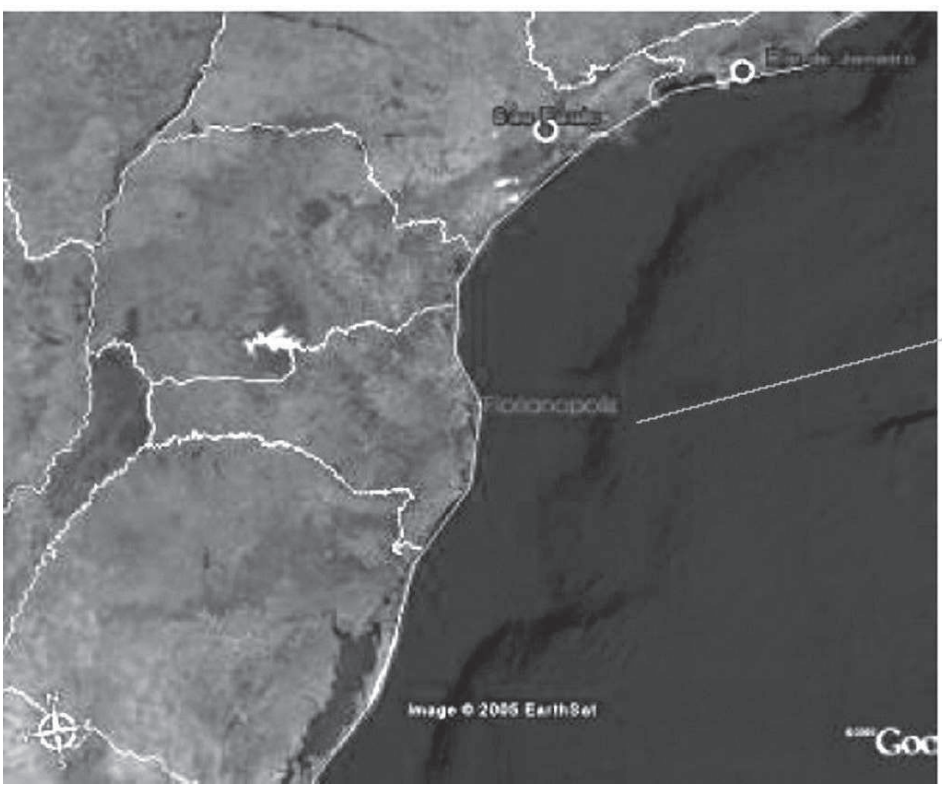

Foto aérea região sul/sudeste - Brasil Fonte: Google earth, 2005

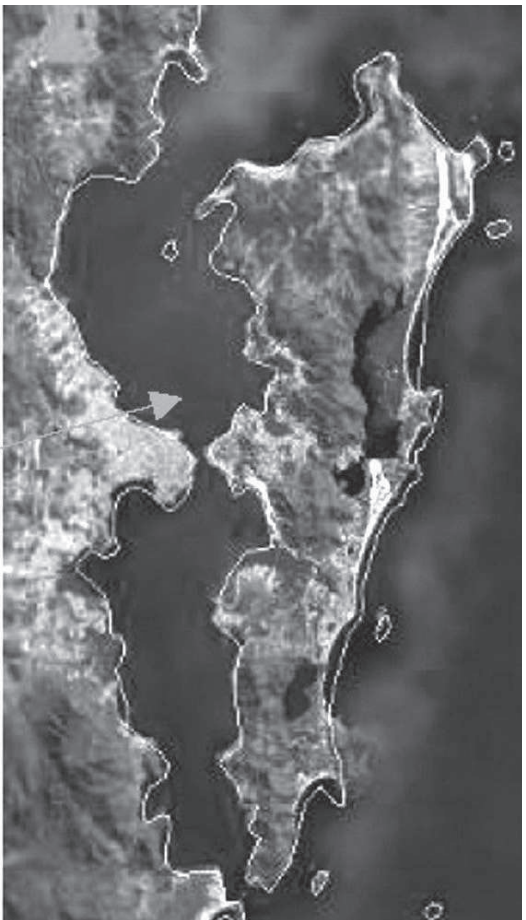

Foto aérea de Florianópolis-SC Fonte: Google earth, 2005

"O Turismo é hoje uma das mais importantes atividades econômicas de Florianópolis. Na temporada de verão 2003/2004 o fluxo de turistas foi de 581.442, sendo que 492.114 nacionais e 89.328 estrangeiros. A receita gerada foi de aproximadamente 113 milhões de dólares, US\$ 89milhões de dólares por turistas nacionais e US\$24 milhões de dólares por turistas estrangeiros." (http://www. pmf.sc.gov.br/cidade/perfil_de_florianopolis/turismo.htm).

Esse setor "vende" a cidade chamando pessoas não só a visitar mas também a morar.

A ocupação da cidade de Florianópolis deve-se a diversos fatores: "...variados são os depoimentos que vão demonstrar de que forma se deu, o desmatamento da llha de Santa Catarina, a 
começar pela necessidade de lenha e madeira para a construção naval e civil além da mobiliária, até chegar à remoção pura e simples das florestas para a organização dos primeiros cultivos agrícolas e dos núcleos urbanos." (CARUSO, 1990, p. 77)

Passando pelos primeiros que povoaram a ilha, agricultores responsáveis pelo primeiro desmatamento em função do seu modo de produzir, pelo aumento da população com a instalação de diversos órgãos estaduais e federais na década de 1960, até "boom" imobiliário devido a "venda" da imagem da cidade para outros estados resultando na especulação imobiliária a partir da década de 1980/1990.

Esse modo de crescimento da cidade resulta em ocupações em áreas de preservação, em áreas sem saneamento básico, sem infra-estrutura urbana, resultando em questões já conhecidas como: polvição da água, falta de água, transito, desmatamento, enchentes, segregação e por outro lado, em alguns casos, trás infra-estrutura ao local.

O bairro de Cacupé é composto de quatro trechos de praias arenosas, com mar interno de baía e manso. Seus limites podem ser definidos, ao norte com a Ponta do Forte, e ao sul, com a Ponta do Cacupé Grande. Suas dimensões entre os dois extremos são de extensão de 1.800 metros e cerca de 1.000 metros em praias.

Sua ocupação iniciou-se por volta de 1978 e vem aumentando até os dias de hoje. Secularmente, as praias do Cacupé, foram utilizadas para pesca e, do lado oposto para morada de nativos, fruto da colonização açoriana, onde cultivavam sobretudo mandioca, o feijão, o milho, algumas frutas, e criavam o gado. Vários engenhos de farinha existiram na localidade.

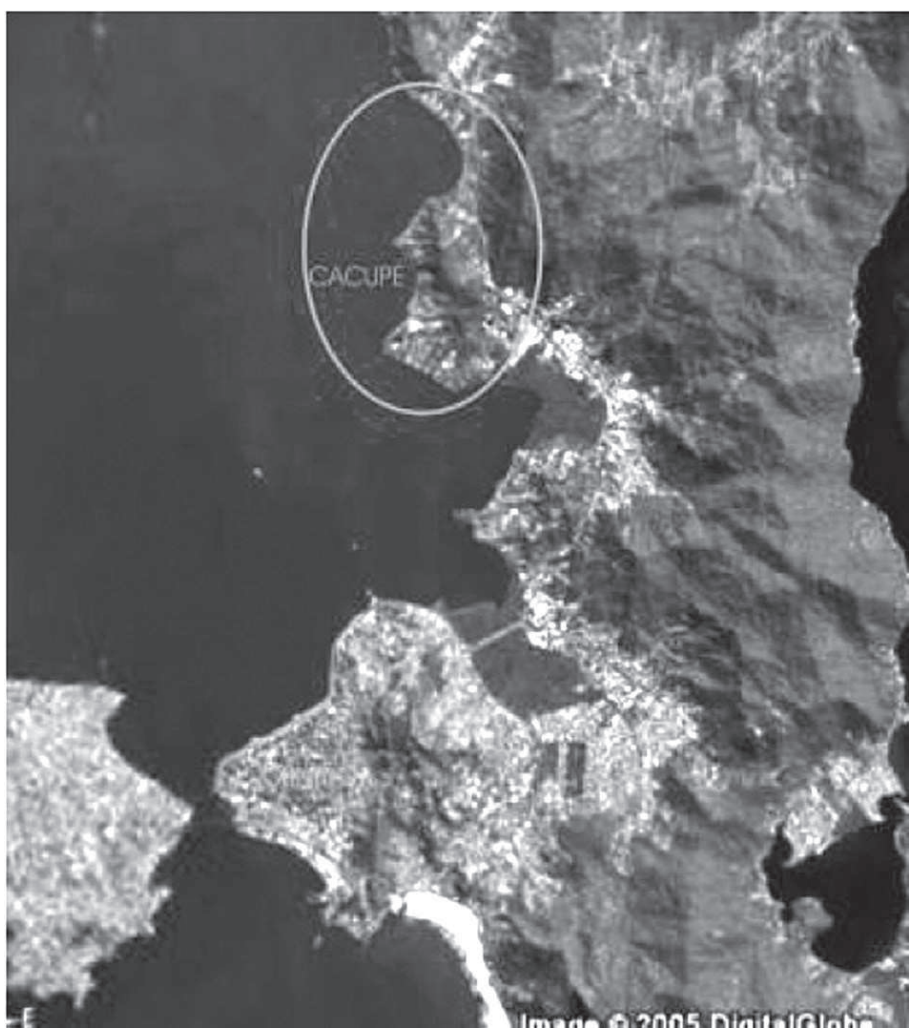

Foto aérea

Fonte: Google earth, 2005

Após essa época de cultivo, com o desenvolvimento da cidade, o bairro passou a ter uma característica de veraneio, famílias de classe média tinham suas casas, sítios para férias, que depois se tornaram moradias permanentes.

Hoje o bairro do Cacupé com 792 hab. está cada vez mais sendo procurado como local residencial por moradores de Florianopolis e por pessoas de outros estados trazidos pela atividade turística. 
Com o aumento de moradias permanentes de "novos moradores" a ocupação não ocorreu diferente do resto da cidade, acelerada. Um dos indicadores desse crescimento é o aumento da implantação de novos empreendimentos na área, sobretudo os condomínios residenciais fechados.

Para a análise dessa transformação do bairro e dessas novas formas de morar foram escolhidos dois condomínios. $O$ critério da escolha foram os que estiveram exaustivamente presentes na mídia durante o ano de 2003/2004. Ambos estão localizados na estrada geral de Cacupé próximo ao Sesc, com vista para o mar e inseridos em local de abundante paisagem natural. Através das imagens abaixo se pode perceber que são condomínios para a classe alta.
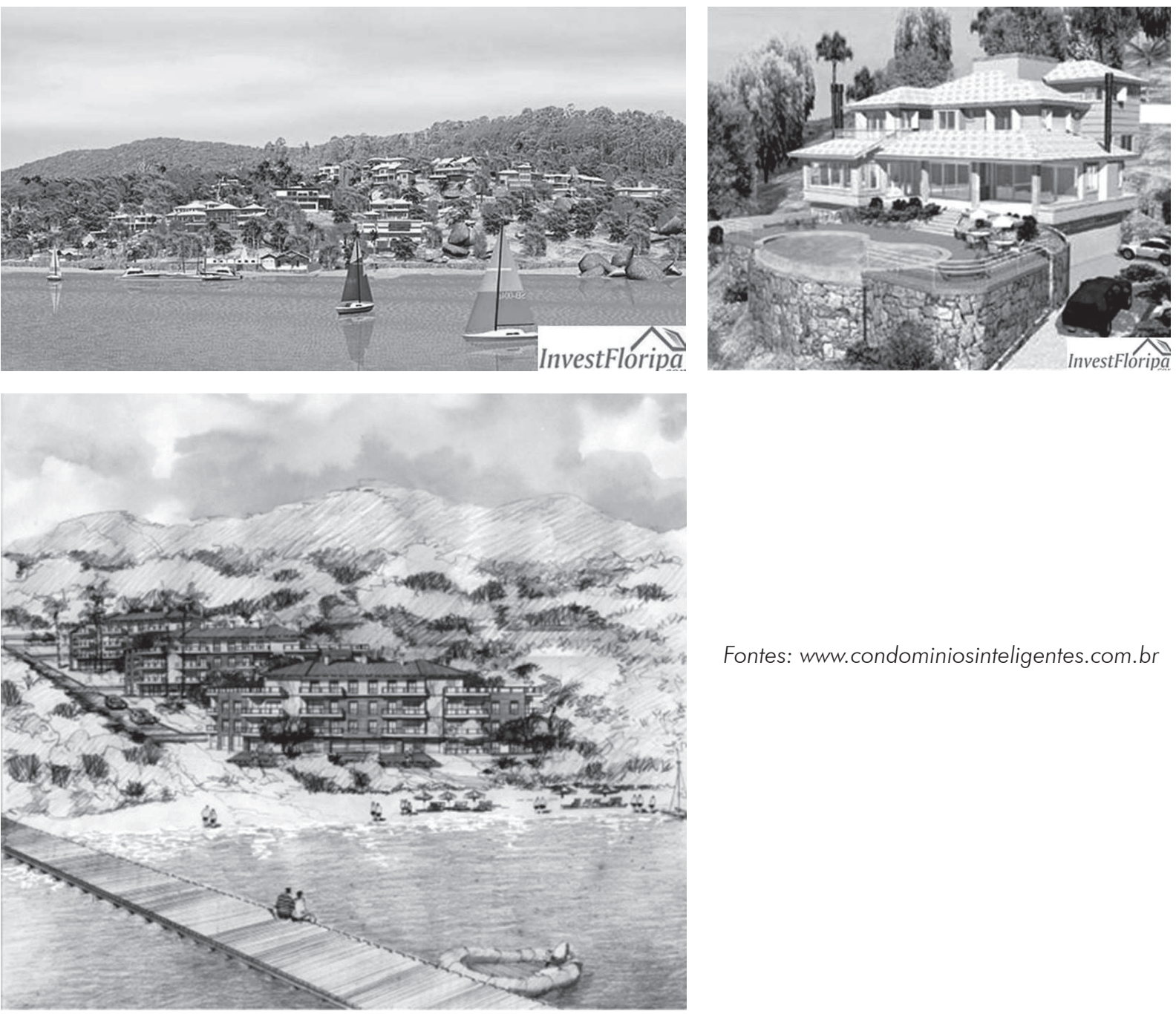

Fontes: www.condominiosinteligentes.com.br

É importante também perceber que as perspectivas "vendem" o local sem seu entorno. Assim é de fácil compreensão que não há, para esses empreendedores, preocupação com a realidade existente, nem com a integração paisagística. São concebidos como "ilhas" dentro da malha urbana pré-existente. E como essas "ilhas" estão se relacionando com a realidade pré-existente?

Através do levantamento na mídia da cidade a reação dos moradores do bairro com relação a essa nova forma de morar é de insatisfação como se observa abaixo em algumas manchetes:

"Protesto reúne moradores contra obra. Associação de Cacupé contesta privatização de espaços públicos." (http://www.an.com.br/ancapital/2003/dez/15/lger.htm)

"Comunidade questiona marina - Moradores querem acesso publico ao empreendimento" (publicado no jornal A Notícia - na capital, em 10/12/03). 
Observa-se portanto uma grande transformação do bairro que ocorreu em pouco tempo incentivado pelo setor imobiliário.

Essas transformações podem ser positivas ou negativas, isso depende de como são implantadas e desenvolvidas.

Cacupé continua caracterizado por um bairro de residências unifamiliares, porém prevê-se um aumento do número dessas residências e não dos acessos ao bairro. Questões como essa que acarretam em problemas como o transito.

Com o objetivo de completar esse estudo e baseado no conceito de que os moradores são parte desse espaço urbano,foram feitas entrevistas. Essas entrevistas foram feitas no entorno imediato dos empreendimentos e com membros da associação de moradores que são pessoas chaves diretamente envolvidas nas transformações do bairro.

Foram feitas as seguintes perguntas: 1- Há quanto tempo você vive no bairro de Cacupé?; 2 - Porque você escolheu Cacupé para morar?; 3 - Já mudou de residência neste mesmo bairro?; Se sim, por quê?; 4 - Você acha que durante esses anos que mora aqui o bairro melhorou ou piorou? Por quê?; 5 - Você acha positivo esses condomínios fechados que estão surgindo no bairro?

\section{A região das entrevistas:}

Primeiramente as 27 entrevistas aplicadas foram divididas em grupos por tempo de moradia no bairro a fim de homogeneizar a analise das respostas dos moradores, uma vez que teriam vivenciado períodos semelhantes no desenvolvimento do bairro.

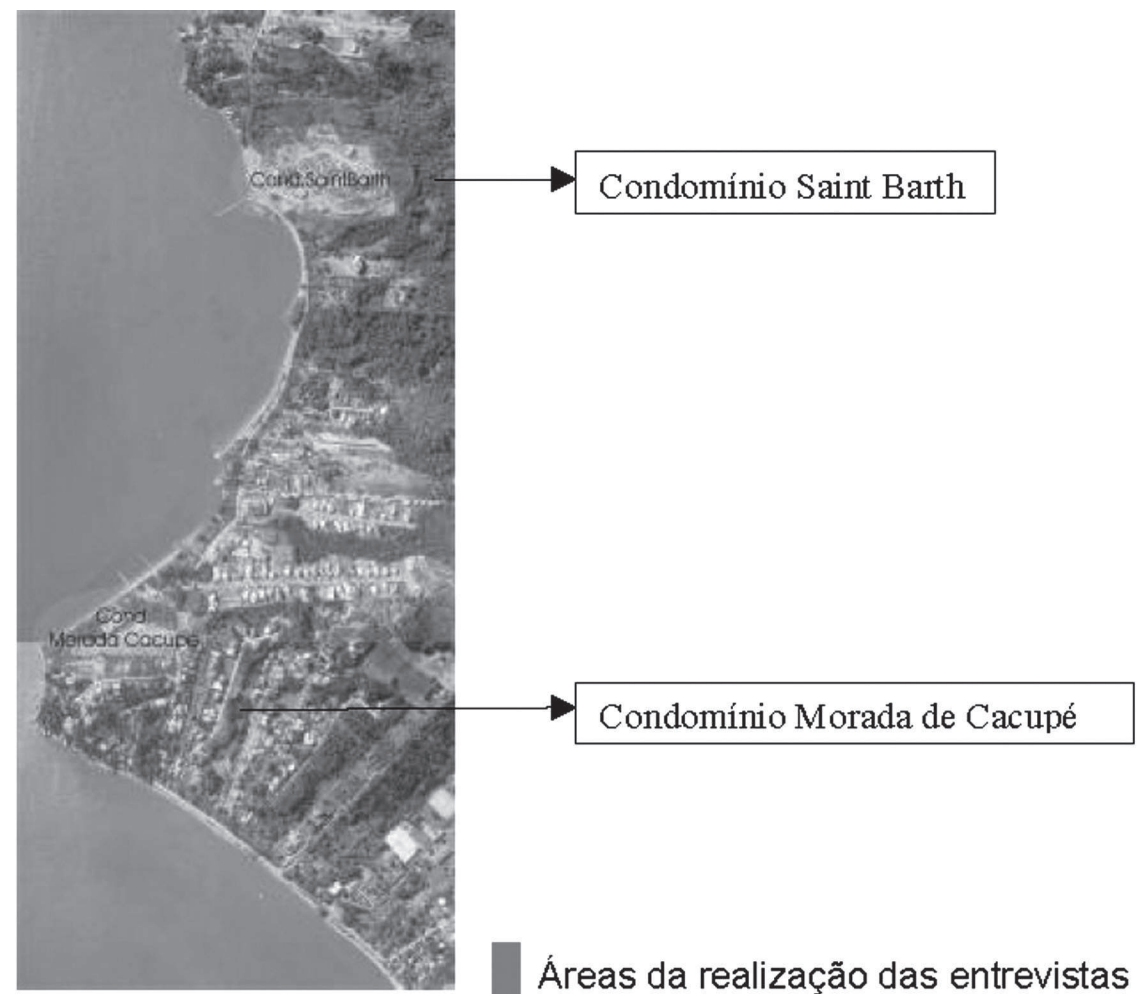

Foto aérea do bairro

Fonte: IPUF, 2005

O resultado quanto ao tempo de moradia o número de entrevistados é bem diversificado. Moram até 10 anos $28 \%$ dos entrevistados, entre 10 e 20 anos 37,50\% e a mais de 20 anos 35,3\%.

Isso mostra que mais de 1/3 dos entrevistados são moradores antigos e permanecem no bairro assim como os novos estão presentes. 
motivo que os entrevistados moram nesse bairro é em $68,78 \%$ dos entrevistados devido a grande presença paisagem natural e tranqüilidade. Essa opinião independe do tempo em que se vive no bairro.

Nenhum dos entrevistados mudou de residência no mesmo bairro, portanto dentre os entrevistados nenhum deles vendeu sua casa a grandes empreendedores. É importante observar que alguns moradores antigos possam ter vendido suas propriedades e mudado para outro bairro, porém isso não foi possível constatar nestas entrevistas e portanto não resultando em dado significativo.

Na questão quanto a transformação do bairro, 28,10\% dos moradores mais antigos, mais de 20 anos de permanência no bairro, pensam que houve uma melhora, principalmente quanto a equipamentos de infra-estrutura. Os mais novos, que moram até 10 anos no bairro, 12,50\% não vêem essa melhora e pensam que piorou, pois o bairro cresce sem planejamento ocorrendo muito desmatamento, ocupação de áreas de preservação, descaracterização do bairro quanto à classe social, falta de saneamento básico, etc.

Com essa transformação vieram os condomínios, os novos lugares para morar. Dos entrevistados que moram a mais de 20 anos $21,87 \%$ vêem essas novas construções positivas para o bairro porque oferecem novos empregos e mais infra-estrutura. Para os que moram até 10 anos $16 \%$ são indiferentes a esse tipo de edificação, $6 \%$ levantaram a questão que falta infraestrutura para suportar essa transformação e outros $6 \%$ pensam que trás infra-estrutura. Para os que estão lá entre 10 e 20 anos 16\% são indiferentes e levantam a questão de falta de infra-estrutura e a não identidade com o bairro, e 16\% acham negativo para o bairro também pela mesma razão dos que são indiferentes. 6,25\% dos entrevistados acham positivo, porque aumenta a oferta de empregos.

\section{Conclusão}

O objetivo deste trabalho foi descrever e analisar a dinâmica do processo de transformação da cidade junto à população que nela reside.

Florianópolis é uma cidade que apresenta natureza insular, com longa faixa litorânea e um percentual considerável de espaço natural ocupado por construções ou destinado a reservas ambientais. A cidade se desenvolveu criando pólos urbanos, com bairros destinados às classes média e alta, na parte central. Segundo o IPUF, 42\% do território da ilha de Santa Catarina são constituídos por diversas reservas ambientais, reduzindo, assim, o espaço destinado à moradia.

O rápido desenvolvimento do setor imobiliário, que hoje comanda grande parte do ordenamento da cidade, determina "novos lugares para morar".

A transformação da cidade está ligada, inicialmente, como se comportaram os gestores municipais, principalmente no que se refere à expansão imobiliária, isso contribuiu para que os problemas se agravassem, tendo em vista que, durante muito tempo às construções foram erguidas sem que houvesse uma interferência adequada do poder público municipal.

Cacupé, objeto de analise dessa transformação em Florianópolis, passou de um bairro para classe média, onde a paisagem natural e a tranqüilidade eram a principal característica, para um "novo lugar" para morar. A classe alta que antes não tinha interesse no local, hoje, com a proposta dessas novas formas de moradia, busca cada vez mais o bairro.

Com essa transformação surgem as "ilhas" dentro do bairro, os condomínios fechados. Que não se relacionam com o entorno. Porém traz uma melhora da infra-estrutura urbana do bairro, como por exemplo o aumento da oferta de serviços. 
Sendo assim, as transformações ocorrem de forma acelerada, criando novos lugares para morar e novas formas de morar. E nesse caso não se relaciona com a realidade pré-existente. E através das entrevistas foi possível analisar como a sociedade está envolvida nesse processo de transformação.

As "ilhas" trazem a segregação dentro do mesmo bairro. Por outro lado, o bairro inserido numa paisagem natural e tranqüilidade, sem infra-estrutura urbana suficiente, assiste a uma melhora considerável com a implantação dessas "ilhas". Diante dessa falta de informação que a cidade está se transformando, e surgindo os "novos lugares" para morar. Constatou-se a falta de conhecimento por parte dos moradores, de que é possível um crescimento planejado e mais justo para todos com a participação da sociedade.

Hoje tornar a cidade justa para todos é possível a partir do Estatuto da Cidade, que regulamenta os artigos 182 e 183 da Constituição Federal e tem como objetivo a democratização do espaço no país através instrumentos, urbanísticos, tributários e jurídicos, que auxiliarão na reforma urbana e que podem garantir efetividade ao Plano Diretor.

Naturalmente a lei sozinha não resolverá todos os problemas presentes hoje na cidade, mas possibilita a sociedade compreender o processo de transformação urbana e sobretudo se posicionar frente a ela. Para assim transformar a cidade de forma mais justa e equilibrada para todos.

\section{Bibliografia}

BURLE MARX, Roberto. Arte e Paisagem - Conferências escolhidas. São Paulo: Nobel, 1987.

CARUSO, Mariléa Martins Leal. O desmatamento da llha de Santa Catarina de 1500 aos dias atuais. 2. ed. Florianópolis: Ed. da UFSC, 1990.

COELHO, Maria Célia Nunes. Impactos ambientais em áreas urbanas - Teorias, conceitos e métodos de pesquisa. In: GUERRA, Antônio José T.; CUNHA, Sandra Baptista da (Orgs.). Impactos ambientais urbanos no Brasil. Rio de Janeiro: Bertrand Brasil, 2001.

CULLEN, Gordon. Paisagem urbana. Lisboa: Edições 70, 1983.

IPUF - INSTITUTO DE PLANEJAMENTO E URBANIZAÇÃO DE FLORIANÓPOLIS. Disponível em: <http://www.ipuf.sc.gov.br >. Acesso em: dez. 2003.

JORNAL A NOTÍCIA. Disponível em <http://www.an.com.br/ancapital/2003/dez/15/lger.htm>.

LOBATO CORREA, Roberto. O espaço urbano. São Paulo: Ática, 1989.

LYNCH, Kevin. A imagem da cidade. Lisboa: Edições 70, 1982.

OLIVEIRA, Dulce Eugênia de. Brasil - Constituição Federal 1988. São Paulo: Ed. Iglu, 2000.

PREFEITURA MUNICIPAL DE FLORIANÓPOLIS. Disponível em:

<http://www.pmf.sc.gov.br/cidade/perfil_de_florianopolis/turismo.htm>. Acesso em: 26 jul. 2005;

$<$ http://www.pmf.sc.gov.br/index.php?link=-perfil\&sublink=demografia $>$. Acesso em: 26 jul. 2005. 